\title{
A função juntiva da preposição sem: especialização de uso em orações adverbias reduzidas de infinitivo
}

Marta Anaísa Bezerra Ramos ${ }^{a}$

Camilo Rosa Silva ${ }^{b}$

\begin{abstract}
Resumo
Neste artigo, focalizamos o emprego dos transpositores sem e sem que, objetivando mostrar o processo de recategorização da preposição sem, que assume função juntiva em orações adverbiais reduzidas de infinitivo, embora a tradição gramatical só admita que sem é um item conjuncional quando, junto ao nominalizador que, integra a locução conjuntiva. A partir da análise de uma pequena amostra de dados, constituida de textos argumentativos - artigos de opinião e entrevistas - apresentamos indícios que evidenciam a recategorização sintático-semântica desse item. Para este estudo, lemos criticamente o ponto de vista que alimenta a tradição gramatical e, sob um pensamento de base funcionalista, buscamos explicar as motivações estruturais e cognitivas que pressionam a mudança experimentada por esses itens linguísticos.
\end{abstract}

Palavras-chave: preposição, conjunção, função juntiva, gramaticalização. 


\section{Introdução}

O objeto de estudo deste artigo se insere em uma das áreas temáticas bastante exploradas pelas abordagens ditas funcionalistas - a dos estudos morfossintáticos, especialmente, o fenômeno da fluidez das classes gramaticais, que culmina na gramaticalização de itens linguísticos, principalmente os adverbiais. Discutimos o estatuto categorial do sem, forma gramatical tradicionalmente classificada como preposição, que rege um sintagma nominal, habilitando-o a desempenhar função de adjunto (adnominal ou adverbial). Se esse transpositor rege uma sentença, significa ter incorporado uma nova função, em um outro nível gramatical, a de conjunção, o que se evidencia no contexto das orações adverbiais reduzidas de infinitivo, uso especializado da preposição sem que pode ser explicado pela teoria da gramaticalização como caso de extensão de função.

Como o valor conjuncional da unidade sem que já é reconhecido, dado o entendimento de que a preposição, agregada ao nominalizador que, constitui uma locução conjuntiva, interessa-nos, aqui, apontar indícios formais que ratifiquem a tese de que o item sem, ao estabelecer elos oracionais, recategoriza-se como conjunção. Por essa razão, prestamos atenção especial às propriedades formais da preposição e da forma verbinominal infinitivo.

Em virtude da delimitação imposta para este artigo, não nos estendemos na caracterização das orações adverbiais, também denominadas estruturas hipotáticas, mas cabe uma referência a Castilho (2010) que, ao distinguir três tipos estruturais ${ }^{1}$ de sentenças que integram a subordinação, define

${ }^{1}$ As outras estruturas mencionadas por Castilho (2010) correspondem a (i) estruturas encaixadas em que uma oração introduzida por uma conjunção integrante serve de complemento do verbo de outra oração, a matriz, estando em relação argumental - são as substantivas, ou completivas; e (ii) estruturas encaixadas em que uma oração introduzida por um pronome relativo modifica um sintagma nominal antecedente, estando em relação de adjunção - são as adjetivas restritivas, ou relativas; as adverbiais como estruturas em que não há encaixamento, estando uma oração em relação de adjunção com outra, servindo-lhe para adicionar uma informação ou circunstância. Assinala, ainda, Castilho (op. cit.) que estas, se comparadas às subordinadas substantivas e adjetivas, têm uma ligação mais fraca em relação à matriz, mas, de outro modo, são mais suscetíveis às necessidades do discurso. Considerando-se os parâmetros universais de independência/dependência sintática propostos para diferenciar a coordenação da subordinação, bem como o critério de encaixamento, sob uma visão escalar, as adverbiais se situam entre as coordenadas e as subordinadas. 
${ }^{2}$ A preposição sem é avaliada, conforme Ilari (2008, p.667), como menos gramaticalizada sob a alegação de ter baixa frequência de uso e manter-se fixa ao sentido original de negação. De outro modo, Castilho (2004, p.1) a inclui no grupo das medianamente gramaticalizadas. O critério utilizado para agrupar as preposições em três pontos da escala de gramaticalização - as mais, as medianamente e as menos gramaticalizadas - tem relação com a diferença de comportamento desses elementos. Assim, no primeiro grupo estão as preposiçõ̃es "que se comportam exclusivamente como preposições (como parece ser o caso de de, em, a, para, com, por)" e nos outros dois as que assumem outra função, a exemplo de conjunção.

${ }^{3} \mathrm{Na}$ proposta de Givón (1986), a determinação de pertença de um item a uma categoria baseia-se no critério de similitude e não de igualdade. Uma vez entendido que certos itens representam melhor que outros uma dada categoria gramatical, e que o menor número de traços não exclui um item daquela categoria (trata-se apenas de elemento menos típico), conclui-se que é exatamente a propriedade do contínuo funcional que possibilita o trânsito entre as classes.
Nessa perspectiva, trazemos para análise, neste artigo, uma pequena amostra de estruturas adverbiais sob as formas reduzida e desenvolvida, introduzidas pelos transpositores sem e sem que, coletadas em textos argumentativos (artigos de opinião e entrevistas), veiculados em periódicos semanais, objetivando: (i) ilustrar alguns contextos estruturais que permitem constatar a recategorização da preposição sem como conjunção, independentemente da presença do nominalizador que; além de (ii) expor as múltiplas relações semânticas inferidas das orações interligadas por esses conectores.

Dois fatos motivaram a eleição desse objeto de estudo: (i) a percepção de que, embora a locução sem que, em diferentes contextos, expresse diferentes sentidos ${ }^{2}$, a tradição gramatical lhe destina pouca atenção, limitando-se a registrar um só valor, que ora é o de condição, ora o de concessão; e (ii) a sobreposição quantitativa, em textos jornalísticos de caráter argumentativo, da estrutura reduzida em comparação à estrutura desenvolvida.

Na sequência deste texto, apresentamos algumas considerações teóricas que põem em relevo a não discretude das categorias gramaticais, seção (2), bem como a caracterização das formas gramaticais em foco, seção (3), seguindo-se, na seção (4), a reflexão em torno do objeto de análise, sendo esta subdividida em dois blocos, abordando em (4.1) as propriedades formais e em (4.2) as propriedades semânticas, de modo a esclarecer a requerida recategorização do sem.

\section{Preposição e conjunção: um exemplo de fluidez categorial}

A tradição gramatical acomoda os elementos nas diferentes classes com base nas semelhanças entre conjuntos de traços morfossintáticos e semânticos. Por outro lado, os vários deslizamentos de itens de uma classe para outra põem em xeque a visão de que as categorias são discretas; esses desvios não ocorrem de forma abrupta, nem implicam, necessariamente, casos de mudança categorial, sendo explicados pela teoria da gramaticalização como extensão de função. Esses casos fronteiriços encontram abrigo na teoria dos protótipos, que, pressupondo a noção de gradação ou contínuo categorial $^{3}$, concebe o item que ostenta o maior número de traços responsáveis pela atribuição de uma classificação como 
protótipo, sendo este tomado como parâmetro para organização dos outros itens em diferentes categorias.

Vislumbramos uma perspectiva de Gramaticalização como a defendida por Traugott (2014, p. 100):

Gramaticalização é o desenvolvimento de expressões procedurais, entre elas as expressões de tempo, aspecto, modalidade, caso, pronomes pessoais, complementizadores e outros conectivos. Também se refere ao estudo de tal desenvolvimento. Expressões procedurais têm significados abstratos que sinalizam relações linguísticas, perspectivas e orientação dêitica. Dependendo da visão de gramática adotada, a gramaticalização também inclui o desenvolvimento de marcadores pragmáticos como marcadores de fronteiras (por exemplo, bem), construções-comentário (por exemplo, eu acho) e tag questions (por exemplo, né?).

Barreto (1999), ao tratar do processo de gramaticalização das conjunções do português, dedica um espaço, em sua tese, para situar a classe das conjunções no conjunto das classes, e, à medida que expõe as propostas de classificação das palavras, vai ficando clara não só a proximidade entre as preposições e as conjunções, como também, a razão de alguns desencontros no processo classificatório. Entre as conclusões a que chega Barreto (op. Cit., p.163), uma especificamente sobre as conjunções é que elas "[...] foram, desde o início, classificadas como elementos de ligação, inicialmente ao lado das preposições, pronomes e artigos e, por fim, apenas ao lado das preposições como elementos de conexão de palavras ou sentenças".

Também a classe das preposições é propensa à variação, mesmo no caso do sem, que não introduz argumentos como o fazem as preposições mais gramaticalizadas $a$, de, em, com... Assim, importa fazermos referência aos trabalhos de Poggio (2002) e Romero (2009), relativos à preposição em foco.

Poggio (2002, p. 221), analisando o processo de recategorização do sem, destaca que essa preposição participa da formação da locução adverbial (sem dúvida), da locução conjuntiva (sem embargo) e ainda da locução conjuntiva (sem que). Neste último caso, ocorre recategorização sintática porque a preposição passa a relacionar, além de vocábulos, orações; e recategorização semântica, porque passa a assumir novos sentidos, a saber, negação de consequência e condição.

Romero (2009), por sua vez, a partir de um estudo diacrônico do português brasileiro em que focaliza o processo 
de gramaticalização/lexicalização/semanticização do sem em comparação ao com, tendo como corpus textos dos séculos XV e XIX, explica que a preposição sine originou, no português, prefixo, preposição e conjunção. Na condição de conjunção, a autora esclarece que, no século $\mathrm{XV}$, esse é um uso restrito em orações reduzidas de infinitivo, surgindo décadas depois a locução conjuntiva sem que, fato motivado, segundo Romero (op. Cit., p.551), pela "expansão do uso de que como uma espécie de complementizador universal, iniciada no latim vulgar". Além disso, "desde as primeiras ocorrências, no século XIV, todas as orações introduzidas por sem que exigiam o verbo no subjuntivo, uso que se manteve no século XIX e permanece ainda hoje". (ibid., p.551)

Em se tratando do valor semântico, convém ressaltar, com base em Poggio (2002, p.102), que há um desacordo entre os estudiosos quanto à caracterização das preposições em palavras plenas ou palavras vazias. Para citar alguns, Tesnière (1976) distingue palavras carregadas de função semântica daquelas que não o são, incluindo as preposições neste segundo grupo (palavras vazias), cuja função é "indicar, precisar ou transformar a categoria de palavras plenas e reger as relações entre elas". Pottier (1962), de outro modo, iguala-as aos outros signos de sentido pleno. Há, ainda, autores, como Borba (1971), para quem a preposição atualiza seu valor, no sistema da língua, a depender do contexto em que se insere.

\section{Preposições e conjunções: uma reflexão em torno das definições}

Considerando os critérios mórfico, sintático e semântico como base para a organização das palavras em categorias gramaticais, situemos as duas classes em foco. Preposição e conjunção se aproximam pelos seguintes traços: são invariáveis, dependentes e estabelecem nexos, ou seja, têm natureza relacional. Essa compreensão prevalece em definições mais tradicionais, como as apresentadas por Barros (1985, p. 211; 213) e Cunha e Cintra (2001, p. 555; 579), reproduzidas no Quadro 1: 


\section{Quadro 1 - Definições que contemplam o aspecto relacional}

\begin{tabular}{|c|l|}
\hline Barros & $\begin{array}{l}\text { Preposição: "elementos de ligação dos consti- } \\
\text { tuintes num sintagma: livro de aula." (p. 211) } \\
\text { Conjunção: "É a palavra invariável que re- } \\
\text { laciona duas orações ou dois termos seme- } \\
\text { lhantes da mesma oração." (p. 213) }\end{array}$ \\
\hline $\begin{array}{c}\text { Cunha } \\
\text { e }\end{array}$ & $\begin{array}{l}\text { Preposição: “[...] palavras invariáveis que relacionam } \\
\text { dois termos de uma oração, de tal modo que o sen- } \\
\text { tido do primeiro (ANTECEDENTE) é explicado ou } \\
\text { completado pelo segundo (CONSEQUENTE)." (555) }\end{array}$ \\
$\begin{array}{l}\text { Conjunção: “[...] vocábulos gramaticais que ser- } \\
\text { vem para relacionar duas orações ou dois ter- } \\
\text { mos semelhantes da mesma oração." (579) }\end{array}$ \\
\hline
\end{tabular}

Divergem, porém, quanto ao tipo de sintagma que conectam. As definições propostas por Perini (1996) e Azeredo (2000), que representam a noção corrente reproduzida em manuais didáticos e cujas limitações serão mencionadas adiante, põem em destaque o aspecto distribucional:

Quadro 2 - Definições que contemplam o aspecto distribucional

\begin{tabular}{|c|l|}
\hline Perini & $\begin{array}{l}\text { Preposição: “é a palavra que precede um SN, forman- } \\
\text { do o conjunto um S Adj. Ou um S Adv." (p. 334) } \\
\text { Conjunção: "é a palavra que precede uma oração, for- } \\
\text { mando o conjunto um S Adv. Ou um SN." (p. 334.) }\end{array}$ \\
\hline Azeredo & $\begin{array}{l}\text { Preposição: "palavra invariável que prece- } \\
\text { de uma unidade nominal - substantivo, prono- } \\
\text { me substantivo, infinitivo -, convertendo-a em } \\
\text { constituinte de unidade maior [...]." (p.144.) }\end{array}$ \\
$\begin{array}{l}\text { Conjunção: "palavra invariável que precede uma } \\
\text { oração desenvolvida, convertendo-a em cons- } \\
\text { tituinte de uma oração maior [...]." (p. 145) }\end{array}$ \\
\hline
\end{tabular}

Depreendemos dessas definições que a natureza da unidade consequente - SN ou SO - é fator determinante para a distinção entre essas duas classes. Mas, além desse aspecto, a caracterização da forma verbal infinitiva é um complicador para o reconhecimento da conjunção, devido à imposição de 
${ }^{4} \mathrm{~A}$ esse respeito, o que ocorre é a percepção do infinitivo como uma 'palavra', no caso, um verbo; e isso fica evidente nas estruturas: a correr/a sorrir; sem chorar/sem sorrir citadas por Bagno (2011), que se refere à combinação "preposição + verbo" para justificar a complexidade da classe dos advérbios, dada a possibilidade de palavras de diferentes classes gramaticais assumirem função adverbial. Portanto, destaca-se que tais estruturas desempenham a função de adjunto adverbial (não orações adverbiais). uma propriedade nominal. Esse traço confere ao transpositor sem, por exemplo, a classificação como preposição.

Por outro lado, ao tratar da sintaxe das formas nominais do verbo, Azeredo (2000) explica que essas formas se assemelham às formas verbais plenas quanto à possibilidade de apresentarem sujeito e objeto, distinguindo-se, porém, destas últimas, por serem inflexíveis quanto à expressão de tempo e modo. O autor (op. Cit., p. 239) ressalva, ainda, que orações sob a forma de infinitivo assumem, por meio do processo de transposição, "o lugar sintático dos sintagmas nominais, e sob a forma de gerúndio ou particípio o lugar sintático dos sintagmas adjetivais e adverbiais" - grifos nossos. Isso significa o reconhecimento de que o emprego das formas nominais do verbo se expande à esfera oracional, mas a omissão do emprego do infinitivo nos sintagmas adverbiais dá margem ao entendimento de que as formas reduzidas de infinitivo só integram orações substantivas.

Castilho (2010, p. 592), por sua vez, lista quatro contextos que são tomados com escopo da preposição: i) sintagma nominal; ii) outro sintagma preposicional; iii) sintagma adverbial e iv) sentença com verbo nominal. Em relação a esse último grupo, exemplifica: "Ao retirar o carro da garagem, vi o ladrão" e "Apesar de abalado com os resultados, mesmo assim continuou dando aulas" (grifos nossos). Constatamos, por meio desse exemplo, que o infinitivo participa de orações adverbiais e não apenas de substantivas.

Em linhas gerais, percebemos da leitura das definições de preposição que, embora alguns autores citem o verbo como uma das unidades subordinadas - um deles é Azeredo, que chega a especificar se tratar do infinitivo -, os exemplos costumeiramente oferecidos como ilustração de sintagmas em que a preposição precede essa forma verbal realmente têm função de adjunto suboracional, sendo, muitas vezes, passíveis de substituição por um substantivo de conteúdo equivalente, a exemplo de "direito de nascer" (de nascimento); "receio de morrer" (da morte); gosto de estudar (do/pelo estudo). Ou seja, há restrição quanto ao reconhecimento da forma de infinitivo como uma unidade verbal, em virtude de se atribuir à forma finita (flexionada) do verbo a função de predicação, restando ao infinitivo a responsabilidade de nomear ${ }^{4}$ uma ação. 
${ }^{5}$ Uma afirmação de Castilho (2009, p. 288), relativa ao estatuto das preposições, põe em evidência a dificuldade em delimitar as propriedades morfossintáticas das palavras. Depois de apontar convergências e divergências entre essa classe e a dos advérbios e conjunções, ele conclui: "Preposições e advérbios são predicadores, isto é, atribuem ao seu escopo propriedades de que ele não dispunha" e ainda "Preposições e conjunções integram a classe dos nexos gramaticais. Ambas ligam palavras e sentenças".
Para finalizar esse tópico, reportamo-nos a Ilari et. Al. (2008 p. 623), que afirmam ser o significado do termo preposição resultante da combinação das palavras prae e ositivo, daí a noção de "posicionar à frente". Normalmente a preposição se coloca à frente de palavras (verbo, substantivo, adjetivo), mas, conforme os autores, ela também pode reger uma sentença introduzida pelo complementizador "que", como ilustra o período: "A circular foi mandada para que todos se manifestassem". Além disso, junto a um acompanhante, a preposição forma um constituinte cuja função é de adjunto. Consideramos oportuno destacar aqui que, se substituirmos a locução conjuntiva, obtendo "A circular foi mandada para todos se manifestarem", o estabelecimento do nexo oracional na estrutura reduzida é assumido pelo para ${ }^{5}$. Logo, nesse contexto, essa forma pode ser entendida como conjunção. É o procuramos defender em relação ao sem.

\section{A multifuncionalidade sintático-semântica dos conectores sem/sem que}

$\mathrm{Na}$ tentativa de demonstrar a multifuncionalidade dos conectores sem e sem que nas estruturas de que fazem parte - orações reduzidas e desenvolvidas, respectivamente -, subdividimos esta seção em dois tópicos, de modo a expor inicialmente os diversos contextos sintáticos representados pelos dois padrões oracionais, com destaque para algumas facetas da estrutura reduzida; em seguida, abordamos os valores semânticos que podem ser inferidos da relação entre as orações introduzidas por esses conectores.

\subsection{Explorando os aspectos formais}

Restringindo-nos por ora às estruturas reduzidas, é oportuno trazermos aqui a afirmação de Macambira (1993) de que o infinitivo pertence ao grupo das categorias duplas, devido à possibilidade de se comportar como substantivo ou como verbo. Assim, admitindo que a ausência de um complemento para a forma infinitiva seria um indício de propriedade nominal do verboide, o infinitivo integraria junto à preposição um sintagma adverbial, na função de adjunção em relação à sentença a sua esquerda. 
Considerando a noção de contínuo categorial, segundo a qual uma forma linguística pode apresentar traços caracterizadores de duas classes distintas, ou seja, para uma forma podem ser atribuídas duas funções, poderíamos conceber que o sem junto a infinitivo, não estando acompanhado de complemento, assume o papel de preposição, e quando acompanhado de complemento, recategoriza-se como conjunção. Os dados a seguir ilustram o primeiro tipo de uso:

(1) [...] Uma mãe dos pobres que aprendeu a mentir, ignorar fatos históricos e até a se equivocar com desenvoltura sem gaguejar. (ÉP, A, 16/08/10)

(2) Se sempre fosse possível trocar um relacionamento por outro, como num passe de mágica, aposto que a maioria das pessoas o fariam sem pestanejar. (IÉ, Entrevista, $22 / 06 / 11)$

As combinações em destaque nos dados supracitados podem ser caracterizadas como estruturas cristalizadas/ integradas e deixam nítida a função de nomeação. Do mesmo modo, essas estruturas cristalizadas podem sinalizar modalização, como revelam os usos representados em (3) e (4), casos em que pode incidir sobre um verbo, uma sentença ou uma porção textual mais extensa. Vejamos:

(3) Sem generalizar, acho que o abuso desses efeitos, que tornam tudo visível demais para o espectador, contribuiu para que o cinema perdesse grande parte de sua emoção e sensação de perigo. (VJ, E, 02/11/11)

(4) Sem querer aliviar em uma grama sequer o peso da primeira conclusão, é preciso admitir que... (VJ, 28/12/11)

Participam, ainda, desse grupo estruturas nas quais o complemento verbal não está expresso, mas pode ser subentendido a partir do contexto (textual ou situacional) "Agiu sem pensar" (nas consequências), confirma esse uso - de modo que o conjunto poderia ser tomado como uma expressão cristalizada, idiomática. Mas, independentemente de ser possível recuperar o complemento/argumento, a ausência deste na superfície da sentença caracterizaria, tal como nos usos descritos anteriormente, a função de adjunção, estando, 
pois, a forma verbal precedida de preposição. Representam essa situação os seguintes usos:

(5) Escritório do Dr. Jairo. Entre sem bater. (ÉP, A, 07/02/11)

(6) O médico, sem perceber, começa a fazer o jogo. (IÉ, E, 26/05/10)

(7) Quando minha mãe engravidou de mim, sem planejar, meu pai descobriu que estava com câncer. (IÉ, E, 21/12/11)

Vale salientar que tanto (6) quanto (7) representam dados em que as expressões negritadas têm um caráter parentético, servindo para introduzir um comentário.

De outro modo, há estruturas em que o infinitivo apresenta características próprias de um verbo pleno, o que se comprova pela possibilidade de depreensão dos constituintes oracionais - sujeito (mesmo que elíptico - $\varnothing$ ) e complementos (objeto direto - simples ou oracional; objeto indireto, complemento relativo, predicativo e locativo). Nesse caso, o infinitivo estaria antecedido não de uma preposição, mas de uma conjunção. Ou seja, é o caráter oracional do adjunto que favorece a identificação do transpositor que precede o infinitivo como conjunção. As sentenças a seguir relacionadas ilustram esse fenômeno:

(8) Outro dia saí com o meu filho de 13 anos e mais uns amiguinhos dele e $\varnothing$ passamos horas juntos, sem ninguém ficar entediado. (Isto É, Entrevista, 02/11/11)

(9) Celulares, redes sociais, sites da internet, são apenas isto: ferramentas. $\varnothing$ Permitem que as pessoas organizem e comuniquem seus pensamentos de maneira mais eficiente, mas não podem nada sem as pessoas a thes dar vida. (VJ, E, 02/03/11)

(10) Época - o que o senhor sugere?

Lazzarini - Um choque institucional para reduzir os custos de intermediação de empresa [...] É preciso ficar mais fácil para um novo empreendedor despontar sozinho, sem recorrer ao Estado. Não acredito que essa feição de capitalismo de laços vá acabar [...] (Época, Entrevista, 06/12/10) 
${ }^{6} \mathrm{O}$ símbolo $(\varnothing)$ sinaliza não apenas elipse, mas também indeterminação ou inexistência de sujeito.

${ }^{7}$ Ilari et al. (2008, p. 638) citam algumas estruturas em que ocorrem as preposições de e $a$, na função de adjunção, reveladoras de regularidades - a primeira apontando para indicação de um período do dia (de manhã, de noite) e a segunda "localizando fatos numa determinada hora do dia" (às dez e meia da noite), usos que segundo os autores demonstram a tendência da língua à formação de frases feitas. Talvez esse fenômeno explique esse tipo de combinação que envolve a preposição em estudo.
(11) O Brasil não teria fortalecido sua posição no FMI sem $\varnothing$ se aliar com a China e com a Índia. (ÉP, A, 19/04/10)

(12) Eike - Há escolas extraordinárias e ensino mais que suficiente para atender às necessidades brasileiras sem precisar treinar lá fora. Os executivos brasileiros foram treinados na guerra nos últimos 20 anos. Os americanos ficaram preguiçosos. (Época, E, 30/05/11)

(13) Fiz um esforço grande para dialogar com a conjuntura eleitoral, mas sem me tornar refém dela. (ÉP, E, 11/10/10)

Sendo assim, nas ocorrências apresentadas, a presença de argumentos - sujeito, em (8) e (9); objeto indireto, em (10); complemento relativo, em (11); locativo, em (12) e predicativo, em (13) - favorecem o reconhecimento de orações, vindo a revelar função conjuntiva. Para reforçar a natureza verbal da forma infinitiva, acrescentamos à discussão outro elemento - o constituinte "sujeito". Uma característica das orações adverbiais reduzidas de infinitivo é a possibilidade da elipse do sujeito ${ }^{6}$, tendo em vista a correferencialidade dos sujeitos das orações matriz e adverbial. Uma vez que não se evidencie ambiguidade semântica ou estrutural no período, o infinitivo se mantém não flexionado. Mas é relevante frisar que as orações reduzidas também exibem sujeitos nãocorreferenciais, como em (9), no qual os verbos passar e ficar estão em relação de concordância com os sujeitos nós, elíptico, ninguém, respectivamente; e em (10), no qual os verbos poder e dar concordam respectivamente com os sujeitos ferramentas e pessoas. Esse fato demonstra que cada oração contém todos os constituintes, o que dá sustentação ao argumento de que o sem atua, nesses contextos, como conjunção.

Por fim, as duas ocorrências transcritas a seguir compreendem usos em que o sem parece estar mais integrado ao verbo, resultando nas combinações: (i) sem + verbos rotulados "suporte" 7 : sem jogar luz, sem levar em conta, sem perder de vista... (14 é um exemplo) e ainda: (ii) (isso) sem + falar, é o caso de (15), ou outros verbos de valor equivalente - contar. Esses usos põem em dúvida a classificação do sem, podendo ser caracterizados como ambíguos, já que ao mesmo tempo em que formam um construto, conduzindo à classificação como preposição, também admitem a permuta com 
a locução conjuntiva, com exceção do sem falar, (sem que jogue luz; sem que leve em conta; sem que perca de vista), daí se poder considerar como conjunção. Vejamos os dados:

(14) Para o presidente do Brasil, as instituições financeiras públicas devem contribuir mais para o crescimento do país sem abrir mão da rentabilidade. (Veja, Entrevista, 03/03/10)

(15) [...] Ainda assim, continuará existindo uma agenda moderna de direitos humanos no Brasil. Quem são as vítimas? Aqueles a quem o Estado nega educação, saúde e segurança, por exemplo. Ou aqueles que morrem nas estradas esburacadas e nas filas dos hospitais. E isso sem falar nos que ainda são torturados nas delegacias ou amontoados nos presídios federais como lixo humano. [...] Esses, que também têm seus direitos suprimidos, não fazem parte da agenda oficial. (IÉ, A, 20/01/2010)

O sentido expresso na oração introduzida por (isso) sem falar, em (15), é de adição/ressalva. Comprovam a ideia de inclusão as paráfrases com e também/ainda ou além de:

(15') [...] Ou aqueles que morrem nas estradas esburacadas e nas filas dos hospitais. E também aqueles que ainda são torturados nas delegacias ou amontoados nos presídios federais como lixo humano. [...]

$\left(15^{\prime \prime}\right)$ [...] Além daqueles que ainda são torturados nas delegacias ou amontoados nos presídios federais como lixo humano. $[\ldots]$

Um exemplo dessa natureza é apresentado em Bechara (1999, p. 506) quando da listagem de alguns valores contextuais da locução sem que, momento em que ele faz a ressalva de que em lugar da locução também se pode usar sem + infinitivo e de que a noção expressa é de MODO. Eis o exemplo: "Estes foram os melhores teatrólogos, sem falar em Machado de Assis e Franklin Távora, mais ilustres no romance e no conto". Esse uso parece revelar a interpretação de acréscimo, e não de modo como sugerido pelo autor, pois, quando da referência aos melhores escritores, há a indicação de alguns teatrólogos, 
fazendo-se a inclusão de dois outros expoentes, sendo estes mais reconhecidos em outro campo - no romance e no conto.

Embora o alvo desta seção não seja analisar o aspecto semântico, essa referência se fez necessária por representar um comportamento exclusivo da estrutura sob a forma reduzida. Para concluir, acrescentamos a posição de Oliveira (2012), que alerta ser o rótulo adição identificador, no português, de estruturas coordenadas e correlativas, não havendo menção à possibilidade de uma oração aditiva ser codificada morfossintaticamente pela subordinação; entretanto, embora, de modo geral, não haja o reconhecimento de orações subordinadas aditivas, em estudos sobre subordinação em inglês, estruturas formadas com "além de" são incluídas nesse grupo, sendo a presença do verbo na forma não-finita um indício de subordinação. Desse modo, a oração ilustrada em (15) pode se enquadrar nesse grupo.

Uma característica das orações reduzidas é a correferencialidade do sujeito, propriedade que favorece o uso do infinitivo não flexionado, mesmo quando o sujeito da oração principal, estando sob a marca de plural, está distante da forma infinitiva. As estruturas desenvolvidas, de que passamos a tratar, apresentam, inversamente, com raras exceções, o sujeito da oração subordinada marcado lexicalmente (sujeito determinado simples), exibindo, algumas vezes, no sintagma nominal, o pronome demonstrativo "isso" com função anafórica. Por conseguinte, ao contrário do modelo anterior, a ocorrência de sujeitos distintos interfere no estabelecimento da concordância, exigindo do escritor maior atenção em relação a esse aspecto, sobretudo, quando o sujeito estiver implícito, pois o uso do verbo na forma finita implica obrigatoriedade de harmonia entre sujeito e predicado.

A ideia de que este segundo tipo de estrutura requer controle da concordância fica mais nítida quando se utiliza a estratégia da paráfrase, transformando orações reduzidas (16) em desenvolvidas, como podemos notar na paráfrase de (16'):

(16) O presidente deixa que se entretenham com isso; sabe quanto é bom, para todos eles, poderem viver o papel de revolucionários com risco zero, sem ter de fugir da polícia e no conforto de cargos em comissão, com cargo oficial e cartão de crédito corporativo. (VJ, A, 27/01/10) 
(16') [...]; sabe quanto é bom, para todos eles, poderem viver o papel de revolucionários com risco zero, sem que tenham de fugir da polícia e no [...]

Na seção subsequente, apresentaremos outras ocorrências de orações sob a forma desenvolvida. Para finalizar esse tópico relativo às propriedades organizacionais, convém destacar que, nas estruturas introduzidas pela locução conjuntiva, sobressaem as seguintes propriedades organizacionais: i) a presença, na maioria das orações, de sujeito expresso por nome ou pronome, determinando o controle da concordância; ii) o uso do verbo no subjuntivo e iii) a forte presença de formas verbais compostas, formas mistas (tempo composto + passiva), além da passiva sintética, com sujeito posposto, o que conduz à sustentação da tese de que as orações desenvolvidas revelam maior grau de complexidade organizacional.

\subsection{Explorando o aspecto semântico}

Nas estruturas oracionais de que fazem parte a locução conjuntiva (estrutura desenvolvida) ou a preposição seguida de infinitivo (estrutura reduzida), vários são os sentidos inferidos das relações entre a oração nuclear e a oração satélite/adendo; porém, apesar da falta de consenso, grande parte dos gramáticos só se refere aos matizes de concessão e consequência. $\mathrm{O}$ valor modal pouco é mencionado nas gramáticas pedagógicas, que só o reconhecem nas orações gerundivas, embora a circunstância de modo seja contemplada na relação dos adjuntos adverbiais. Há gramáticos que fazem a ressalva de que não incluem esse matiz semântico no rol das adverbiais em virtude de a Nomenclatura Gramatical Brasileira excluir tal noção.

Apresentamos, a seguir, alguns dados, três representativos do primeiro padrão oracional, que evidenciam os valores de concessão, condição e negação de consequência, respectivamente; $\mathrm{e}$ três do segundo padrão, indicando, consequência, modo e causa; o valor de adição, específico das estruturas reduzidas, já foi comentado na seção precedente:

(17) A conquista da estabilidade é outro exemplo. O plano real foi uma pequena jóia. Ter congelado a distribuição de renda sem que as pessoas tivessem entendido, ter 
liberado os preços, ter construído todo um equilíbrio no tricô e depois liberado tudo e ele continuar como estava. Foi uma coisa brilhante, um dos mais extraordinários planos de estabilização já construídos. Negar esse fato é uma estupidez. (Época, Entrevista, 08/11/10)

(18) A terceira realidade claramente descortinada por esses dados é a utilização política do setor educação. Não é possível chegar a esse nível sem que haja um esforço deliberado de contratações desnecessárias. Contratações que só ocorrem porque os profissionais da educação são frequentemente utilizados como instrumento político de seus padrinhos. (Veja, Artigo, 12/10/11)

(19) Hoje somos perfeitamente capazes de elevar a taxa de juros e assumirmos as consequências, sem que isso signifique uma perda. Temos integral compromisso com a estabilidade. [...] (Isto É, Entrevista, 12/05/10)

(20) Qual é o caminho para os juros baixos até que essa diferença inexista? Estamos falando de um problema com razões históricas que remontam aos tempos de quase hiperinflação e à série de planos heterodoxos implementados para combatê-la. (...) Foi para saber onde cortar sem produzir efeitos danosos à economia que se instalou no Palácio do Planalto um conselho de gestão coordenado pelo empresário Jorge Gerdau. Esse conselho vai ajudar o governo a produzir mais poupança e a diminuir gastos improdutivos para que se possa investir mais em educação e gastar menos com burocracia e despesas inúteis. (Isto É, E, 27/07/11)

(21) A morte da jornalista Marcela Coutinho é notícia velha. Velha de três semanas. Na noite de 28 de novembro, uma segunda-feira, ela foi covardemente asfixiada. Deixou a vida sem dar o último suspiro. Puseram-lhe um travesseiro na cara. (ÉP, A, 19/12/11)

(22) A que se deve, em primeiro lugar, isso que o senhor qualifica como um empobrecimento musical? A questão começa na transição para o meio digital do que foi efetivamente gravado no estúdio. (...) O resultado é que os músicos se acostumaram com essa baixa resolução e, talvez sem se dar conta, adaptaram sua produção. (VJ, 26/10/11) 
Devemos esclarecer que o conector serve de guia para a apreensão dos diversos sentidos inferidos das relações oracionais, mas a seleção lexical, o tempo verbal, a pausa/ pontuação são outras pistas que contribuem para a inferência de sentidos múltiplos. Cabe acrescentar que, embora a tradição gramatical registre condição e concessão como sentidos prototípicos desses conectores, o que conduz à interpretação de que sejam os valores mais gramaticalizados, nos dados coletados nos periódicos, o segundo matiz foi, de fato, mais recorrente, mas o primeiro teve menor frequência em comparação a outros, a exemplo de consequência e modo. Logo, a recorrência parece ser também um parâmetro indicativo de gramaticalização, daí se poder afirmar que esses dois matizes já teriam se gramaticalizado.

Os processos metafóricos e metonímicos explicam a associação de conteúdos distintos via transferência de significado de um termo concreto para um termo abstrato; em outras palavras, a passagem de um significado referencial para um não referencial, o que representa ganho de complexidade. É esse procedimento que torna possível compreender, por exemplo, como os conectores sem/sem que abrigam os valores de condição e concessão, apontados pela tradição, entre outros como consequência e modo. Como esses valores derivam do sentido primário de ausência e negação de sem, reportamo-nos a Castilho (2009), que aponta a capacidade de atribuir ao seu complemento propriedades de espaço e movimento como o traço distintivo da preposição em relação à conjunção.

Por outro lado, o sentido prototípico de espaço favorece extensões semânticas diversas, via projeções metafóricas, valores que atingem também a locução conjuntiva. Segundo Castilho (op. cit.), o sentido de base espaço/tempo se organiza em conformidade com as seguintes categorias: posição no espaço/ tempo; disposição no espaço/tempo e distância no espaço/ tempo. As duas categorias cognitivas nas quais se enquadra a preposição SEM - disposição e proximidade no espaço/tempo subdividem-se nos eixos: continente/conteúdo, no primeiro caso; longe/perto, no segundo, havendo ainda os papéis temáticos correspondentes: dentro/fora e proximal/distal.

Em relação ao eixo proximal/distal, Ilari et. al. (2008, p. 667) afirmam que as noções que representam essa categoria são expressas normalmente por advérbios, mas quando uma 
${ }^{8}$ De acordo com Tavares (2003, p. 64), à semelhança da abstração e generalização do significado, ocorre a generalização de padrões de uso, o que seria uma consequência da perda de especificidade semântica, porque, sendo o significado abstrato mais maleável às necessidades comunicativas, termina por favorecer "a extensão de sua aplicação para domínios funcionais diversos". determinada noção é expressa por preposições "acarreta noções de copresença para o traço PROXIMAL, e de ausência para o traço DISTAL". Para os autores, por ser difícil imaginar a princípio o esquema imagético espacial para as preposições com e sem, é preciso conceber um esquema espacial como 'presença simultânea em um mesmo espaço'. No caso específico do sem, evoca a noção de ausência em oposição à noção de co-presença, derivando ainda a noção de distância, como evidencia o exemplo por eles citado: "Eu acho que é uma exigência que, que se faz talvez, por deformação já de berço que se tenha sem com isso eu quere(r) banca(r) o esnobe, né," [D2 POA 291] (p. 701).

Nesse sentido, as noções de ausência e negação, próprias da preposição sem se associam, no plano físico, à noção de distância, expandindo-se ainda mais, de modo a abarcar, no plano conceitual, o valor de distância de ideias, ou seja, conteúdos que não se combinam, que contrastam, daí a noção de adversidade ou concessão. $\mathrm{O}$ mesmo tipo de associação se dá com as condicionais, já que a ausência de um requisito determina a validade (ou verdade) do argumento expresso na oração matriz; e com as consecutivas, orações que têm uma proximidade com as coordenadas adversativas, no sentido de que se nega um possível resultado inferido da oração precedente. Logo, a transferência de conceitos de base espacial - ausência e distância - para conceitos mais gerais, como os citados, confirma a direção da mudança rumo à abstração.

Outro processo que explica a transferência de significado são associações que se fazem devido a pressões contextuais, caso em que a mudança é condicionada pelo valor de outros elementos presentes na estrutura linguística, ou que possam ser inferidos da relação entre os componentes que fazem parte de uma dada configuração estrutural. Como um mesmo contexto pode autorizar várias inferências, o conector vai assimilando sentidos diversos, o que leva à generalização do significado ${ }^{8}$, de modo que a interpretação é manipulada de acordo com as necessidades comunicativas. Assim, cabe ao ouvinte, no jogo interacional, filtrar, com base nas pistas deixadas no texto, o viés semântico que, do seu ponto de vista, melhor representa as intenções do escritor. 


\section{Considerações finais}

Da observação das estruturas reduzidas e desenvolvidas, depreendemos regularidades sintáticas em cada padrão. Sendo assim, na estrutura reduzida predominam sujeitos correferenciais, enquanto na reduzida, sujeito expresso; exatamente por exibir sujeito na superfície oracional, a estrutura desenvolvida requer controle quanto à concordância; e, por apresentar verbo finito, implica cuidado quanto à flexão modo-temporal, aspectos esses que não são exigidos na estrutura reduzida.

Por outro lado, o uso de expressões cristalizadas, em que ocorrem os verbos "suporte", que, até podem admitir a paráfrase com a locução conjuntiva, exceto o caso de "sem falar", é bem peculiar à estrutura reduzida. Salientamos que, dentro de um mesmo modelo estrutural, há padrões diferenciados - no caso das estruturas reduzidas, se a natureza nominal do infinitivo sobressai, o item sem recebe o rótulo de preposição; se, de outro modo, o infinitivo, desempenhando o papel de verbo suporte, origina expressão lexicalizada, surge dúvida quanto à natureza da forma verbal (nominal ou verbal). Assim ocorre porque causaria estranheza a flexão modo-temporal, por desfazer a unidade, confusão que se estende à caracterização do conector (se preposição ou conjunção); por fim, se o caráter verbal do infinitivo se sobrepõe, quando da presença de termos argumentais, o item sem assume o papel de conjunção.

Em relação ao aspecto semântico, embora a preposição sem possa preservar o sentido de origem, o que significa que a persistência dos traços primitivos poderia ser um impedimento à ampliação do significado, apresentamos evidências da generalização semântica, incluindo o surgimento de um novo matiz, o de adição, que acarretou mudança na estrutura oracional, pois, apesar de se constituir como informação complementar, não funciona propriamente como estrutura de realce, função típica das adverbiais, mas como estrutura de expansão.

Fica evidente, portanto, que a transferência de significado decorrente de pressões contextuais conduz a novas inferências, comprovando que o conector vai incorporando novas subfunções e perdendo especificidade. Como o uso inovador, com o passar do tempo, torna-se fixo, diz-se que se 
gramaticalizou e novos usos podem dele ser derivados, fazendo o sistema linguístico se renovar.

\section{REFERÊNCIAS}

AZEREDO, José Carlos de. Fundamentos de gramática do português. Rio de Janeiro: Jorge Zahar, 2000.

BAGNO, Marcos. Gramática pedagógica do português brasileiro. São Paulo: Parábola, 2011.

BARRETO, Therezinha Maria Melo. Gramaticalização das conjunções na história do português. Salvador: UFba, Tese de doutoramento, 1999.

BARROS, João de. Gramática da língua portuguesa; Cartinha, Gramática, Diálogo em louvor da nossa linguagem e Diálogo da Viciosa Vergonha. Reprod. facsim., leit., introd. e anot. por Maria Leonor Carvalhão Buescu. Lisboa, Faculdade de Letras, 1971. 482 p. (primeira versão - 1540)

BARROS, Enéas Martins de. Nova Gramática da língua portuguesa. São Paulo: Atlas, 1985.

BECHARA, Evanildo. Moderna gramática portuguesa. 38. ed. Rio de Janeiro: Lucerna, 1999/2003.

CASTILHO, Ataliba T. de. A língua falada no ensino de português. São Paulo: Contexto, 2004.

. de. Para uma análise multissistêmica das preposições.

In: . História do português paulista. Campinas: Unicamp/ Publicações IEL, 2009.

. Nova gramática do português brasileiro. São Paulo: Contexto, 2010.

CASTILHO, Ataliba T. de; ILARI, Rodolfo; NEVES, Maria Helena; BASSO, Renato M. O advérbio. In ILARI, Rodolfo; NEVES, M. H. M. (orgs.). Gramática do português culto falado no Brasil. VOL. 2, Campinas: Unicamp, 2008.

CUNHA, Celso e CINTRA, Luís F. L. Nova gramática do português contemporâneo. Rio de Janeiro: Nova Fronteira, 2001. 
GIVÓN, Talmy. Prototypes: between Plato and Wittegenstein. Em: CRAIG (ed.1986, p.77-102) GEIS, Michael; ZWICKY, Arnold. On invited inference. Linguistic Inquiry, v.2, n.4, p. 561-566, 1971.

HEINE, Bernd; CLAUDI, Ulrike; HÜNNEMEYER, Friederike. Grammaticalization: a conceptual framework. Chicago/London: University of Chicago Press, 1991.

HOPPER, Paul. e TRAUGOTT, Elizabeth. Grammaticalization. Cambridge: Cambridge University Press, 1993.

ILARI, Rodolfo. As conjunções. In: ILARI, Rodolfo; NEVES, Maria Helena Moura (orgs.). Gramática do português culto falado no Brasil. VOL. 2, Campinas: Unicamp, 2008, p. 809-860.

ILARI, Rofolfo; CASTILHO, Ataliba Teixeira de; ALMEIDA, Maria Lúcia Leitão de; KLEPPA, Lou-Ann; BASSO, Renato Miguel. A preposição. In: ILARI, Rodolfo; NEVES, Maria Helena Moura (orgs.). Gramática do português culto falado no Brasil. VOL. 2, Campinas: Unicamp, 2008, p. 623-804.

ILARI, Rodolfo; NEVES, Maria Helena Moura (orgs.). Gramática do português culto falado no Brasil. VOL. 2, Campinas: Unicamp, 2008.

MACAMBIRA, José Rebouças. A estrutura morfo-sintática do português. São Paulo: Pioneira, 1993.

NEVES, Maria Helena Moura. Gramática de usos do português. São Paulo: Editora Unesp, 2000.

OLIVEIRA, Fernão de. Gramática da língua portuguesa. Ed. Crítica, semidiplomática e anastática de Amadeu Torres e Carlos assunção. Lisboa: Academia Portuguesa de História. 2000. (primeira versão - 1536).

OLIVEIRA, Taísa Peres de. A hipotaxe de adição. In: Revista do Gel, São Paulo, v.9, n.2, p. 25-45, 2012.

PERINI, Mário. Gramática descritiva do português. São Paulo: Ática, 1996.

POTTIER, Bernard. Systematique des éléments de relations. Paris: Klincksieck, 1962, 376p. 
POGGIO, Rosauta Maria Galvão Fagundes. Processos de gramaticalização de preposições do latim ao português: uma abordagem funcionalista. Salvador: EDUFBA, 2002.

ROBINS, Robert Henry. Pequena história da lingüística. Trad. De Luiz Martins Monteiro de Barros. Rio de Janeiro: Ao livro Técnico, 1979, 203p.

ROMERO, Nanci. Gramaticalização, lexicalização e semanticização de com e sem. In: CASTILHO, Ataliba Teixeira (org.). História do português paulista. Campinas: UNICAMP/ Publicações IEL, 2009.

TAVARES, Maria Alice. A gramaticalização de e, aí, daí, e então: estratificação/variação e mudança no domínio funcional da seqüenciação retroativo-propulsora de informações - um estudo sociofuncionalista. (Tese de Doutorado). Florianópolis: UFSC, 2003.

TESNIÈRE, Lucien. Élements de syntaxe structurale. 2 éd. rev. et corrigée. Paris: Klincksieck, 1976.

TRAUGOTT, Elizabeth Closs. Gramaticalização: uma entrevista com Elizabeth Closs Traugott. ReVEL, vol. 12, n. 22, 2014. Traduzido por Gabriel de Ávila Othero e Ana Carolina Spinelli. [www.revel.inf.br]. 


\section{Abstract \\ The conjunctive function of the preposition 'sem': specialization of use in reducted infinitive adverbial sentences}

Abstract: In this paper we focus on the use of linguistic items sem and sem que, aiming to show the change process of preposition 'sem', assuming connective function in reducted infinitive adverbial sentences, although the grammatical tradition only admits that 'sem' is a conjuncional item when, next to 'que', integrates a conjunctive phrase. From the analysis of a small sample of argumentative texts opinion articles and interviews - we present clues to evidence the syntactic-semantic change of this item. For this study, read critically the viewpoint that feeds the grammatical tradition and, under the basic functionalist thinking, we seek to explain structural and cognitive motivations that force the change experienced by these linguistic items.

Keywords: conjunctive function; preposition; gramaticalization. 